\title{
Budgeted Health Services for Women: A Community-based Initiative
}

\author{
Desi Adhariani ${ }^{1}$ \\ (desi.adhariani@ui.ac.id ${ }^{1}$ ) \\ Department of Accounting, Faculty of Economics and Business, Universitas Indonesia, \\ Depok, Indonesia ${ }^{1}$
}

\begin{abstract}
This study presents a community-based initiative providing budgeted health services targeted primarily for women from low-income families in an urban area. The health services were provided once a month and covered basic check-up and an examination conducted by a female doctor. During the period of this study, the services were attended by 411 residents, $10 \%$ of them are men. Based on the interviews, the residents gave positive feedback on this initiative as it helps them indicate any sickness symptoms that need to be followed up by a comprehensive examination in primary health care or hospital.
\end{abstract}

Keywords: health services, women, community-based

\section{Introduction}

This study is aimed at presenting and evaluating a community-based initiative providing budgeted health services in an urban area in Depok, West Java. This initiative reflects the changing health care needs of a given population as a response to the change in demographic, economic, social, technological, environmental factors as well as access to health services [1]. The responses towards this change may come from the government's political decision; or personal motivation of certain stakeholders [2].

In regards to the personal motivation of concerned stakeholders, there have been several initiatives on health care needs provided by individual, groups, organizations, and corporate. This study presents the initiative conducted by a group of people in an urban community who provided the health services using independent financing. This type of financing assist the government in catering the affordable and efficient health care needs as financing is of concern to governments everywhere, and a particular challenge for developing countries with more limited government resource base [3]. The community-based health care also assists the residents with limited access and find it difficult to go to the nearest primary health care or hospital due to the costs of transportation associated with it.

The health care initiative is targeted primarily for women from low-income household. This group is viewed as the most vulnerable group in the population as women usually prioritize the health and health care services of other family members over theirs. Such gender equality in the health sector is advancing women's health policies and goals at the global, national, and local level [4]. It also implied that health care is a societal responsibility in order to fulfill the rights of citizens [5]. 
The main research question raised in this study is: What are the perceptions of residents, especially women, attending the community-based health care services about this initiative? More specifically, the detail research questions are:

a. What aspects that women consider important in health services, especially in terms of the need of insurance and medicine?

b. Are there any gender issues in accessing the health services?

c. What are the overall perceptions on the community-based health services?

The questions are answered using a qualitative method through interviews with the health services participants. Before discussing further the method used, a brief literature review is presented in the next section. The discussion and analysis of the results are presented after the Method, concluded with the Conclusion as the last section of this paper.

Gender differences in health have been documented in previous studies. One of the findings is that women live longer but suffer from poorer health conditions [6]. Several contributing factors are typically the combination of biological, social-structural, psychosocial, and behavioral characteristics and conditions [7]. The most frequently cited determinant is the socioeconomic status (e.g., poverty status, educational level, and health insurance status) as generally, persons from higher social status have better health due to better access to resources necessary to prevent and cure illness.

The socioeconomic profile of women shows that this group has limited access to healthrelated resources. Women are also less likely to make an effort to seek appropriate and early health care for the disease [8]. This group is also found to be more vulnerable as they are likely to be more illiterate, unemployed, and dependent on others.

Considering all drivers above, health services provided by governments or intervention from community initiatives can help open access for women. This study focusses on the community initiatives on health services, though the scale is smaller than governments' health services, it can reach more residents, especially women, to provide basic health check to prevent a more serious illness or provide recommendations to visit the nearest hospital or primary health care if the examinations indicate the need.

\section{Methodology}

This study is an observation of a community-based health service conducted by several concerned medical and non-medical persons in Tugu, an urban village located in Cimanggis sub-district, Depok City, West Java, Indonesia. Having an area of $504 \mathrm{~km} 2$, this village has a number of populations of 88,416 people. In 2011, the Environmental Health Risk Assessment study (EHRA) conducted by the government states that there are two out of 63 urban villages in Depok which are stated to have high potential for health due to the influence of sanitation and hygiene its citizens, namely Kukusan Village in Beji sub-district, and Tugu Village, in Cimanggis sub-district [9].

The community-based health service is organised by a non-government organization that gets the fundings from donors. Although the fundings are only in a small amount compared to other organizations or corporations, the health services activities have been run for several years. The program involves several medical and non-medical volunteers who provide their time to run the program once a month (or, in a certain period it can be once a week) visiting 
residents around Depok City. The health services were conducted in one of the resident's house in each neighbourhood.

This research is a prototype case study in the hope that it can become a role model for other budgeted health services in other areas in Indonesia. The observation was conducted for five months in early 2019, and the health care services were provided in a different neighborhood (RT - Rukun Tetangga) at Community Unit 2 (RW-rukun Warga 02) in Tugu urban village. The mobile nature of the services enables the reach for residents whose residents are far away from health centers. Although the primary target is women, men are not prohibited from joining. There are 411 residents attending the health services in the study period, with $10 \%$ of them are men. In-depth interviews were conducted with 98 residents to know their perceptions on the community-based initiative of the health services. The results of the interviews are analyzed qualitatively by determining the themes frequently uttered by the participants.

\section{Results and Discussion}

The profile of residents attending the health services in the study period is as follows.

Table 1. Profile of participants of health services program

\begin{tabular}{lcc}
\hline & Number & Percentage \\
\hline $\begin{array}{l}\text { Female } \\
\text { Male }\end{array}$ Total & 369 & $90 \%$ \\
& $\underline{411}$ & $10 \%$ \\
$<20$ years old & 3 & $\underline{\mathbf{1 0 0 \%}}$ \\
$21-40$ years old & 111 & $1 \%$ \\
$41-60$ years old & 198 & $27 \%$ \\
$>60$ years old & 99 & $48 \%$ \\
$\quad$ Total & $\underline{\mathbf{4 1 1}}$ & $24 \%$ \\
\end{tabular}


Based on the data in Table 1, women as the primary target of the program is accounted for $90 \%$ of all participants. Almost half of the participants are dominated by the age bracket of 41 60 years old. The health services provided are the basic ones, which are the examination on:

1. Blood pressure

2. Body weight

3. Blood sugar

4. Gout

5. Cholesterol

6. Consultation with a doctor

The themes stated by 98 participants who are interviewed are quoted and analyzed below.

\subsection{Healthcare insurance}

Most of the participants have JKN (Jaminan Kesehatan Nasional) - The Indonesian National Health Insurance administered by BPJS (Badan Penyelenggara Jaminan Sosial Social Insurance Administration Organization). There are two versions of BPJS: BPJS Kesehatan (the successor of PT Askes) and BPJS Ketanagakerjaan (the successor of Jamsostek). The first administers JKN for non-employees/self-employed/informal workers and the latter for employees. Both are government insurance companies formed by the Law No. 24 the Year 2011. Participants claim that the national insurance has lessened their burden on health a bit, even though in some cases they should still provide additional payment for uncovered services.

\subsection{The need to take medicine}

The health services program is designed to provide basic health check and provide recommendations of the appropriate medicine, or recommendations to visit the nearest primary health care or hospital if the examination indicates a more severe health problem. The program is not designed to give medicines due to limited fundings, and there is also an ideal reason to educate people to be wise in consuming medication, especially for an ailment which can heal itself in a few days; such as mild fever or headache. However, most of the participants demand that they can go home bringing medicines after the health check. They feel that they increase their self-confidence to recover soon. This implies the need for education on the wise use of medicines.

\subsection{Gender issues}


The interviews with men attending the health services confirm that women in their household have a more limited access to health services. This is mostly due to the time needed to access the facilities while at the same time they have to take care of the children. The time inflexibility were not experienced by men as they can freely go for working and were easily finding time to visit the primary health care or hospital to consult their health.

\subsection{Overall perceptions on the community-based health services}

Even though the program only provides a basic health check, all participants view it positively as it helps them indicate a health problem, and they can also have health education delivered by the doctor. They demand that the program can be continuously run regularly and still free of costs. They also require health education to cover information on healthy food and the wise consumption of medicines.

\section{Conclusion}

This study is aimed at presenting a community initiative on health services for women in low-income household. The initiative is organized by several concerned persons in a nongovernment organization in Depok, West Java. During the observation period of 5 months in early 2019, there are 411 residents who use the services, $90 \%$ of them are women. Based on interviews with 98 participants randomly selected from the residents, it reveals a positive view of the initiative based on several reasons. First, it helps them prevent and detect certain illnesses based on the basic health check provided. Second, it gives them health education on the treatment of certain illnesses. They recommend that the program can be run regularly in the future and suggest some required topics for health education. The implication of this study is given the positive view of the participants; there is a need to educate residents on the wise way of consuming medicines and on several ways to maintain health, including from consuming healthy food and maintaining healthy life styles.

Acknowledgments. This study is funded by the 2019 Community Engagement Grant from The Indonesia Ministry of Research, Technology, and Higher Education. The support is highly appreciated.

\section{References}

[1] Kingma, M.: Economic incentive in community nursing: attraction, rejection, or indifference?. Human Resources for Health. pp. 1-12 (2003)

[2] Hornby, P., Sidney, E., \& World Health Organization. Motivation and health service performance. Geneva: World Health Organization (No. WHO/EDUC/88.196. Unpublished) (1988) 
[3] Borghi, J., Munthali, S., Million, L. B., \& Martinez-Alvarez, M. Health financing at the district level in Malawi: an analysis of the distribution of funds at two points in time. Health policy and planning. pp. 59-69 (2017)

[4] Wofford, D., MacDonald, S., \& Rodehau, C. A call to action on women's health: putting corporate CSR standards for workplace health on the global health agenda. Globalization and health. pp. 1-12 (2016)

[5] O'Rourke, T. W. Lost in the Health Care Reform Discussion: Health Care as a Right or Privilege. American Journal of Health Education. pp. 138-141 (2017)

[6] Read, J. N. G., \& Gorman, B. K. Gender, and health inequality. Annual Review of Sociology. pp. 371-386 (2010)

[7] van Wijk, C. M. G., Huisman, H., \& Kolk, A. M. Gender differences in physical symptoms and illness behavior: A health diary study. Social Science \& Medicine. pp. 1061-1074 (1999)

[8] Fikree, F. F., \& Pasha, O. Role of gender in health disparity: the South Asian context. British Medical Journal. pp. 823-826 (2004)

[9] RPJMD Kota Depok, accessed from

http://perpustakaan.bappenas.go.id/lontar/file?file=digital/143286-[_Konten_]-Konten\%20D76.pdf 